\title{
Structural and Morphological Behaviour and Study of the Colorimetric and Reflective Properties of Commercial Inorganic Pigments
}

\author{
Ketlyn Wolfart Borth ${ }^{\mathrm{a}}$, Rayane Ferreira ${ }^{\mathrm{a}}$, Douglas Galante ${ }^{\mathrm{b}}(\mathbb{D})$ Fauze Jacó Anaissi $^{\mathrm{a}, *(\mathbb{D})}$ and \\ Marcia Gabriela Pianaro Valenga ${ }^{a}$ (D) \\ ${ }^{a}$ Departament of Chemistry, Universidade Estadual do Centro-Oeste, Guarapuava, PR, Brazil. \\ ${ }^{b}$ Brazilian Synchrotron Light Laboratory, Brazilian Center for Research in Energy and Materials, Campinas, SP, Brazil.
}

Received 11 December 2018, revised 13 August 2019, accepted 6 September 2019.

\begin{abstract}
Characterization of colourful materials must include reflective, spectroscopic and colorimetric properties. Therefore, powder commercial pigments $\left(\mathrm{Xadrez}^{\circledR}\right)$ were investigated to identify their structure, morphology, composition and real colour, in order to use them as patterns to new materials. Results from $\mathrm{X}$-ray diffraction, $\mathrm{X}$-ray fluorescence spectroscopy and electronic spectroscopy indicated the compounds that give colour to the pigments brown, red, yellow and black as, generally, iron oxides, in the phases hematite $\left(\alpha-\mathrm{Fe}_{2} \mathrm{O}_{3}\right)$, goethite $(\alpha-\mathrm{FeOOH})$ and magnesium ferrite $\left(\mathrm{MgFe}_{2} \mathrm{O}_{4}\right)$, in different proportions. Meanwhile, blue and green pigments contained copper phthalocyanine and other compounds responsible for their colour. Commercial pigments presented different degrees of solar reflectance: the highest value was $44.7 \%$ to white pigment and the lowest $2.2 \%$ to black pigment. Colorimetric data made it possible to calculate the real colour of the pigments, using the free software of ColorMine library, and, then, to assess the colour of new synthetic pigments.
\end{abstract}

KEYWORDS

Inorganic pigments, iron oxides, phthalocyanine, NIR reflectivity, colorimetry.

\section{Introduction}

Dyes and pigments are products used to add colour to materials and food in industry. In addition they have an important role in coatings, for example, protection against corrosion. ${ }^{1,2}$ Both are easily mistaken, because their major application is to provide colour. The differences between them are, generally, the size of the particle and solubility in the medium: pigments have larger particle size than dyes, but, on the other hand, dyes are more soluble than pigments. ${ }^{3-6}$

These differences affect the product, if the application in paints and coatings is considered. Pigments provide, simultaneously, covering, opacity, tinting and colouration, while dyes only provide tinting. Furthermore, the power of tinting and resistance to light must be considered in the application of each material. For that, dyes have bigger tinctorial power and pigments have more resistance to light. ${ }^{3}$ Because of this, dyes are more used in textile and food industries, while pigments are used in paints, plastics, glasses and ceramics. ${ }^{2,7}$, More specifically, pigments have been known for their colour properties since antiquity, when pieces of rocks containing iron oxides were used in cave paintings. ${ }^{9}$ The broad variety of colours in this segment is due to the facility of obtaining several kinds of pigments, such as organic, ${ }^{10}$ inorganic, ${ }^{9}$ natural, ${ }^{1}$ synthetic ${ }^{12}$ and artificial ${ }^{1}$.

The humankind evolution and the more sustainable environmental effects during production made the synthetic pigments nowadays the most manufactured. ${ }^{1,9}$ Because the production process can be controlled, it was possible to generate a variety of pigments possessing properties that amplify their application in covering and colouration. ${ }^{10,13}$ Therefore, this work aims at the characterization and the study of commercial pigments,

* To whom correspondence should be addressed. E-mail: anaissi@ unicentro.br to identify their composition, morphology, structure and real colouration, to make it possible to compare new materials and conventional pigments.

\section{Experimental}

\subsection{Commercial Pigment Samples}

Powder pigments samples $\left(\mathrm{Xadrez}^{\circledR}\right)$ in the colours yellow, blue, brown, black, green and red were purchased in the local market of Guarapuava-PR. Since it is used to give colour to plaster and grout, powder plaster was employed as white pigment reference. ${ }^{14}$ The samples (Fig. 1) were pulverized in a mortar, sifted through 65 mesh and subjected to structural, spectroscopy and colorimetric characterization.

\subsection{Characterization Techniques}

X-ray diffraction (XRD) was performed using a Bruker D2 Phases $X$-ray diffractometer, employing a copper cathode $(\lambda=$ $1.5418 \AA$ ), which was operated at a power of $30 \mathrm{kV}$ and current of $10 \mathrm{~mA}$. Data were collected by step scanning over a $2 \theta$ range from $20^{\circ}$ to $70^{\circ}$, with an increment of $0.05^{\circ} \mathrm{s}^{-1}$. The software Match! and the crystallography files from the (ICSD) were used to identify the phases. The estimation of crystallite size was calculated from the Debye-Scherrer equation $(k=0.9$ e 1.39$)$, by measuring the width at half-height (FWHM) of the most intense pick of the diffractogram. ${ }^{15}$

The X-ray fluorescence spectroscopy (XRF) analyses were performed using a Shimadzu EDX-720 X-ray fluorescence spectrometer equipped with a $\mathrm{Rh}$ tube $(50 \mathrm{~W})$ and high resolution $\mathrm{Si}(\mathrm{Li})$ state detector. For the analysis, the samples were set in a plastic sample holder with a support film of Mylar (polysty- 


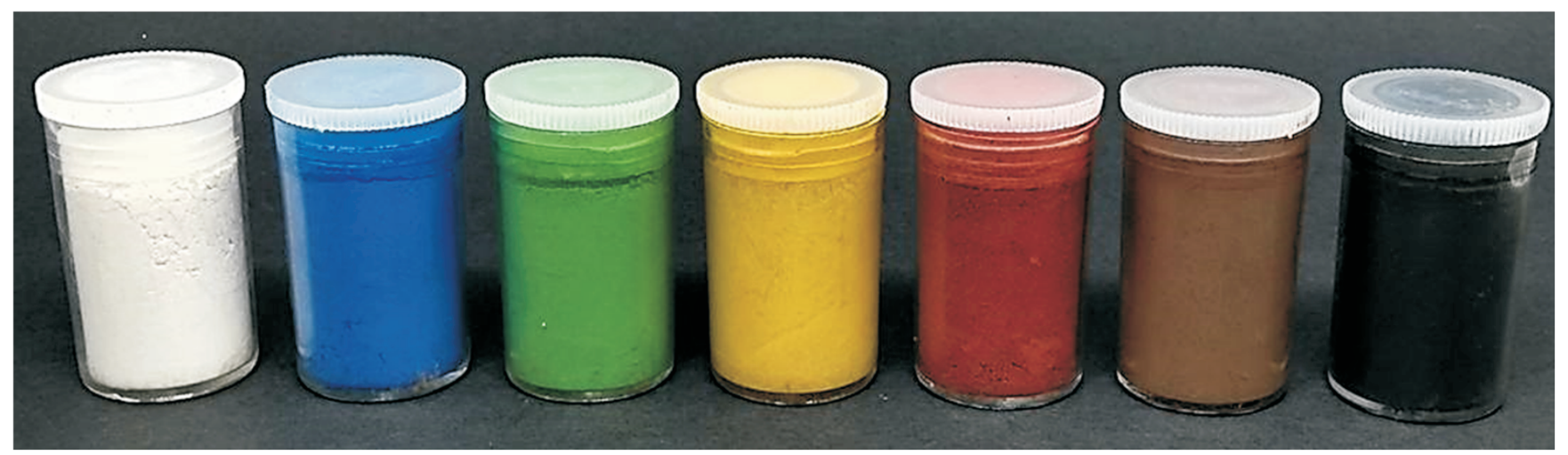

Figure 1 Flasks containing plaster and powder colourful commercial pigments.

rene) and put into the carousel of the equipment. The data were used to estimate the composition of the samples.

The morphology of the samples was observed by scanning electron microscopy (SEM). The images were acquired with a FEI (Quanta 650) microscope, with $2.5 \mathrm{~nm}$ and $30 \mathrm{kV}$ beam. The samples were previously dispersed in isopropyl alcohol using an ultrasound bath and deposited on silicon (100).

Electronic spectroscopy (UV-Visible) and colorimetry (CIE $\left.L^{*} a^{*} b^{*}\right)$ measures, for powder samples, were performed in an Ocean Optics USB 2000 optical fibre spectrophotometer, equipped with tungsten-halogen lamp and silicon $(350-720 \mathrm{~nm})$ and germanium (720-1050 nm) detectors. For suspended samples, a Shimadzu UV-1800 spectrophotometer was used.

The diffuse reflectance of powder pigments was measured by near infrared spectroscopy, using a Perkin Elmer (Frontier FT-IR/NIR) spectrophotometer, with spectral resolution of $16 \mathrm{~cm}^{-1}$ and accumulations of 32 scans. The reflection spectra were scanned in a range of 700 to $2500 \mathrm{~nm}$. The spectral reflectance data were used to calculate the surface solar reflectance of each sample. For that, the correction of the reflectance intensity to each wavelength was made using the solar spectrum pattern ASTM G173, from (ASTM). ${ }^{16}$

\section{Results and Discussion}

\subsection{X-Ray Diffraction (XRD)}

Figure 2 presents the X-ray diffractograms of the pigments. The results were compared and indexed with the diffraction patterns from ICSD database. The crystallographic profiles of the blue, the green and the brown pigments exhibited more than one phase, due to the presence of dispersing compounds in its constitution, such as calcium and magnesium carbonates and silicon oxide. This white matrix is not responsible for the colour of the materials. ${ }^{17}$ Meanwhile, the samples of the yellow, the red and the black pigments had the predominance of only one iron oxide phase, which was goethite $(\alpha-\mathrm{FeOOH})$, hematite $\left(\alpha-\mathrm{Fe}_{2} \mathrm{O}_{3}\right)$ and magnesium ferrite $\left(\mathrm{MgFe}_{2} \mathrm{O}_{4}\right)$, respectively. The difference of crystallinity among the materials was not numerically significant. However, the estimation of the mean crystallite size, which was calculated to extremes of structure factors (k), presented a difference of $45 \mathrm{~nm}$ between the highest and the lowest value. ${ }^{14}$ For both structure factors, crystallites in the nanometric order were observed (Table 1).

\subsection{X-Ray Fluorescence (XRF)}

Table 2 presents the results of the elemental composition obtained by XRF, in which the main elements of each sample are highlighted. The results were in accordance with XRD data, that is, all pigments had iron in its composition, and this was the major component for most of the samples. The results also indicated that copper is the compound responsible for the colour of the blue and the green pigments, since copper phthalocyaninea metalized macrocyclic compound with a copper atom - is applied, according to the literature, as pigment. The colour of this organometallic varies from blue to green, depending on the aromatic rings substitution: in the blue pigment, the copper is not substituted; in the green pigment, since the iron percentage is high, a mixture of blue copper phthalocyanine and yellow goethite $(\mathrm{FeO}(\mathrm{OH}))$ is suggested. ${ }^{18,19}$

Table 1 XRD parameters: crystallinity degree and estimative of crystallite dimension of plaster and commercial pigments.

\begin{tabular}{cccc}
\hline Pigments & \multirow{2}{*}{ Crystallinity/\% } & \multicolumn{2}{c}{ Crystallite size/nm } \\
\cline { 3 - 4 } & & $\mathrm{k}=0.9$ & $\mathrm{k}=1.39$ \\
\hline Plaster & 89.5 & 40.9 & 59.0 \\
Blue & 85.1 & 65.6 & 94.5 \\
Green & 83.9 & 44.4 & 56.7 \\
Yellow & 79.7 & 39.3 & 64.2 \\
Red & 85.8 & 51.2 & 73.9 \\
Brown & 78.7 & 44.4 & 64.1 \\
Black & 79.7 & 20.0 & 28.8 \\
\hline
\end{tabular}

Table 2 Results of elemental analysis by X-ray fluorescence of plaster and colourful commercial pigments.

\begin{tabular}{|c|c|c|c|c|c|c|c|c|c|c|c|c|}
\hline \multirow[t]{2}{*}{ Pigments } & \multicolumn{12}{|c|}{ XRF data/\% weight } \\
\hline & $\mathrm{Si}$ & $\mathrm{P}$ & $S$ & K & $\mathrm{Ca}$ & $\mathrm{Ti}$ & $\mathrm{Cr}$ & $\mathrm{Mn}$ & $\mathrm{Fe}$ & $\mathrm{Cu}$ & $\mathrm{Zn}$ & $\overline{\mathrm{Sr}}$ \\
\hline Plaster & & 4.84 & 32.76 & & 61.78 & & & & 0.19 & & & 0.41 \\
\hline Blue & 29.09 & & & 7.26 & 51.51 & 1.66 & & & 3.29 & 6.91 & 0.26 & \\
\hline Green & 20.07 & & & 2.80 & 42.72 & & & 0.13 & 32.74 & 1.27 & 0.27 & \\
\hline Yellow & & & & & & & & 0.15 & 99.85 & & & \\
\hline Red & & & & & & & 0.19 & 0.17 & 99.08 & 0.37 & 0.17 & \\
\hline Brown & & & & & 4.65 & & & 2.86 & 91.29 & 0.18 & 1.01 & \\
\hline Black & & & & & 3.11 & & & 5.28 & 90.12 & & 1.48 & \\
\hline
\end{tabular}




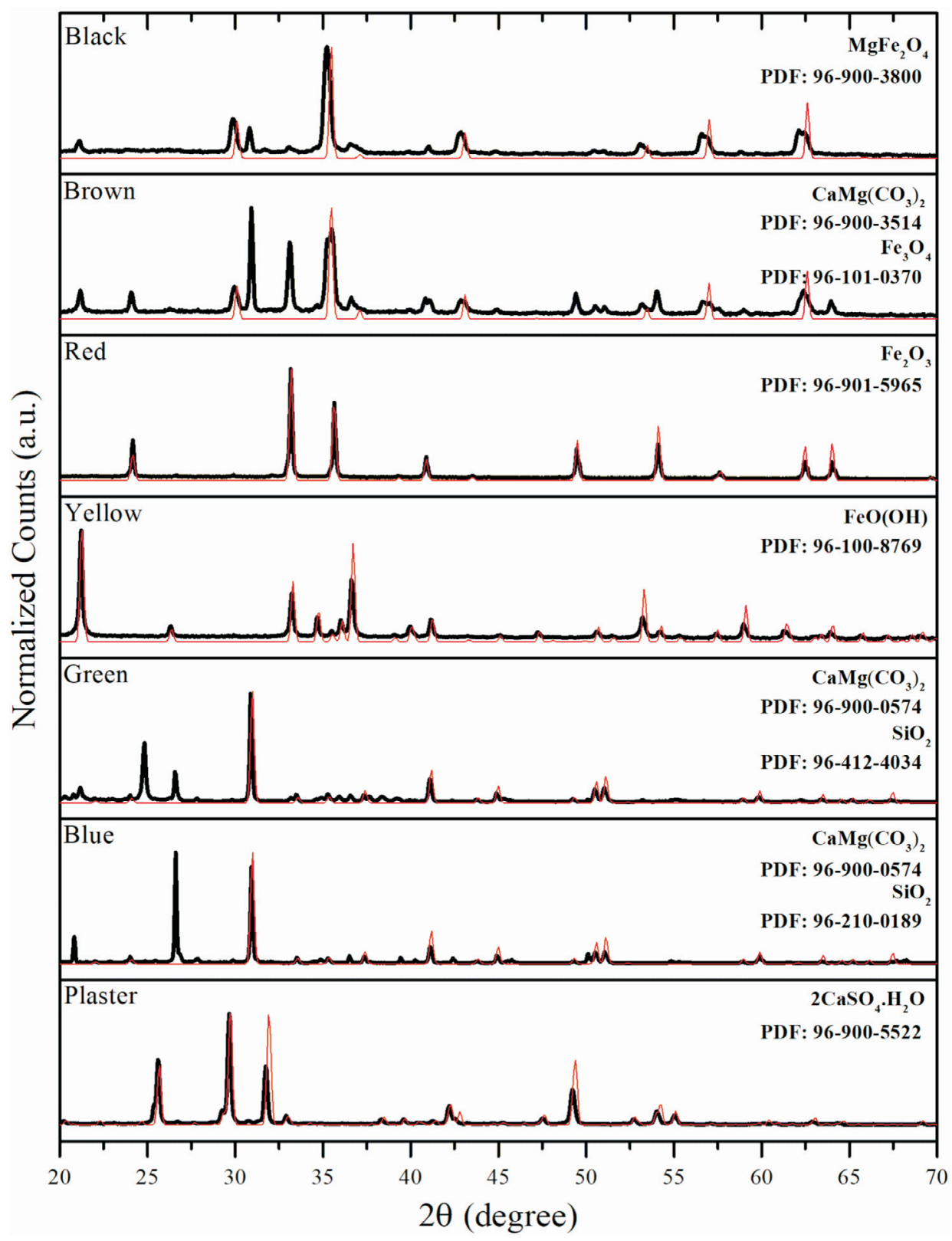

Figure 2 X-ray diffraction profile of plaster and colourful commercial pigments.

\subsection{Electronic Spectroscopy (UV-VIS)}

The absorbance spectra (Fig. 3a) of the blue and the green pigments presented typical bands of the macrocyclic phthalocyanine in the range between 200 and $400 \mathrm{~nm}$ (B-band or Soret). These bands are related to the transition of charge between the central metal and the phthalocyanine rings (MLCT) and the transitions $-{ }^{*}$ of the macrocyclic ring, since there is a high electronic density, due to the 18 electrons from the macrocyclic ring A nother characteristic band (Fig. 3b) is the Q-band, in the range between 550 and $800 \mathrm{~nm}$, due to the electronic transitions from $\mathrm{HOMO}$ to LUMO in the orbitals of the phthalocyanine rings. ${ }^{20-22}$

The reflectance spectra of the powder pigments were obtained between 400 and $780 \mathrm{~nm}$ (Fig. 4). The bands are more pronounced in the main region of each colour (blue, green, yellow and red). The reflectance spectra of the plaster, the black and the brown pigments did not present a defined band, because of the total or low reflectance of every wavelength. This phenomenon occurs due to the composition and the phases identified in the $\mathrm{XRD}$, that were calcium sulfate, goethite, hematite, magnetite, magnesium ferrite and copper phthalocyanine. ${ }^{17,18,23}$

\subsection{Scanning Electronic Microscopy (SEM)}

The morphological characterization from SEM images (Fig. 5) made it possible to observe that the particles present different shapes in each pigment. The SEM image of plaster (Fig. 5a) showed that the crystals exhibited lamellar, irregular and bimodal shapes, suggesting the possibility of a mixture of $\alpha$ and $\beta$ plaster, since in $\alpha$ plaster predominates needle morphology and in $\beta$ more heterogeneous shapes. ${ }^{24}$ The SEM images of blue and green pigments (Fig. 5b,c) corroborated XRD data, due to the presence of bimodal morphology, from the additional phases in the composition. Even though similar compounds were identified in these pigments, the particles had distinct shapes, which means the compounds that give colour to the materials are influenced directly by morphology. For the other pigments, homogeneous and monomodal shapes were identified, with particles of needle shape (Fig. 5d) and porous spheres (Fig. 5e,f,g).

\subsection{Near Infrared (NIR)}

The diffuse reflectance between the wavelengths of 750 and 

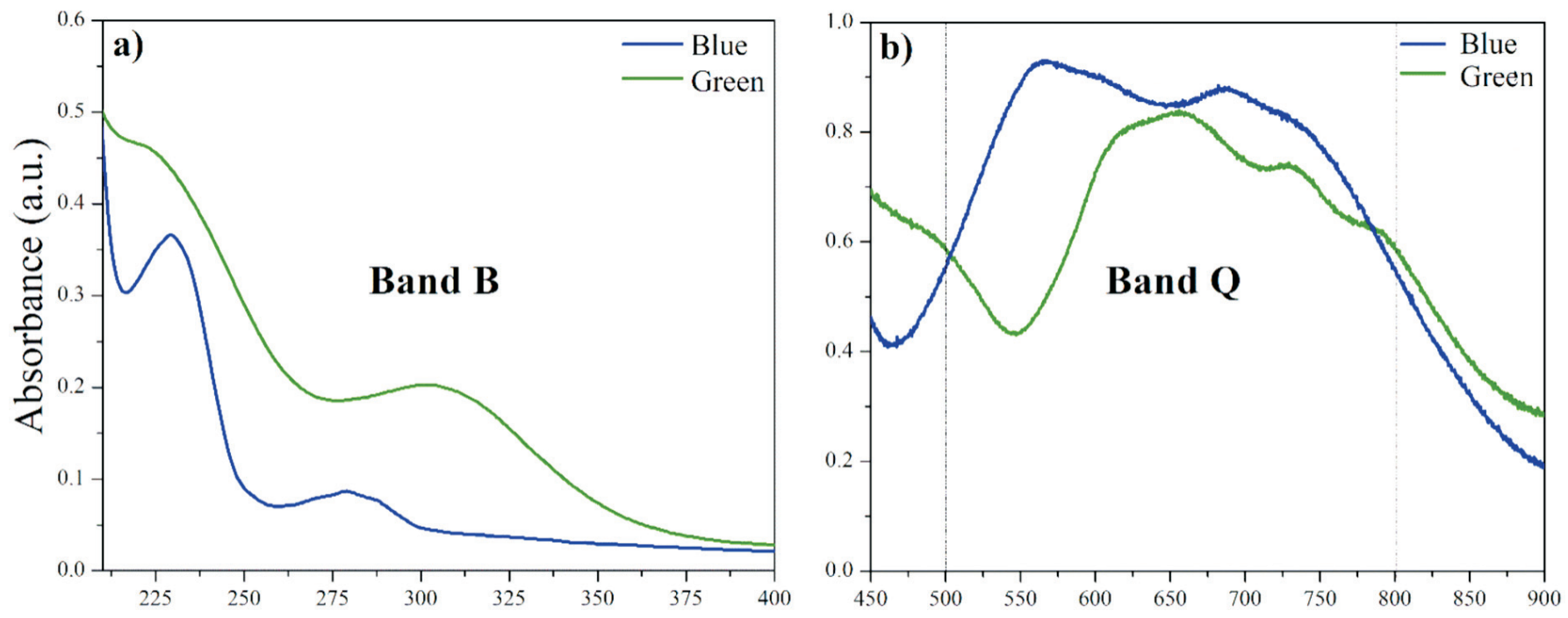

\section{Wavelength (nm)}

Figure 3 Electronic spectra of blue and green pigments in solution (UV-Vis), in absorbance mode. (a) B-band and (b) Q-band.

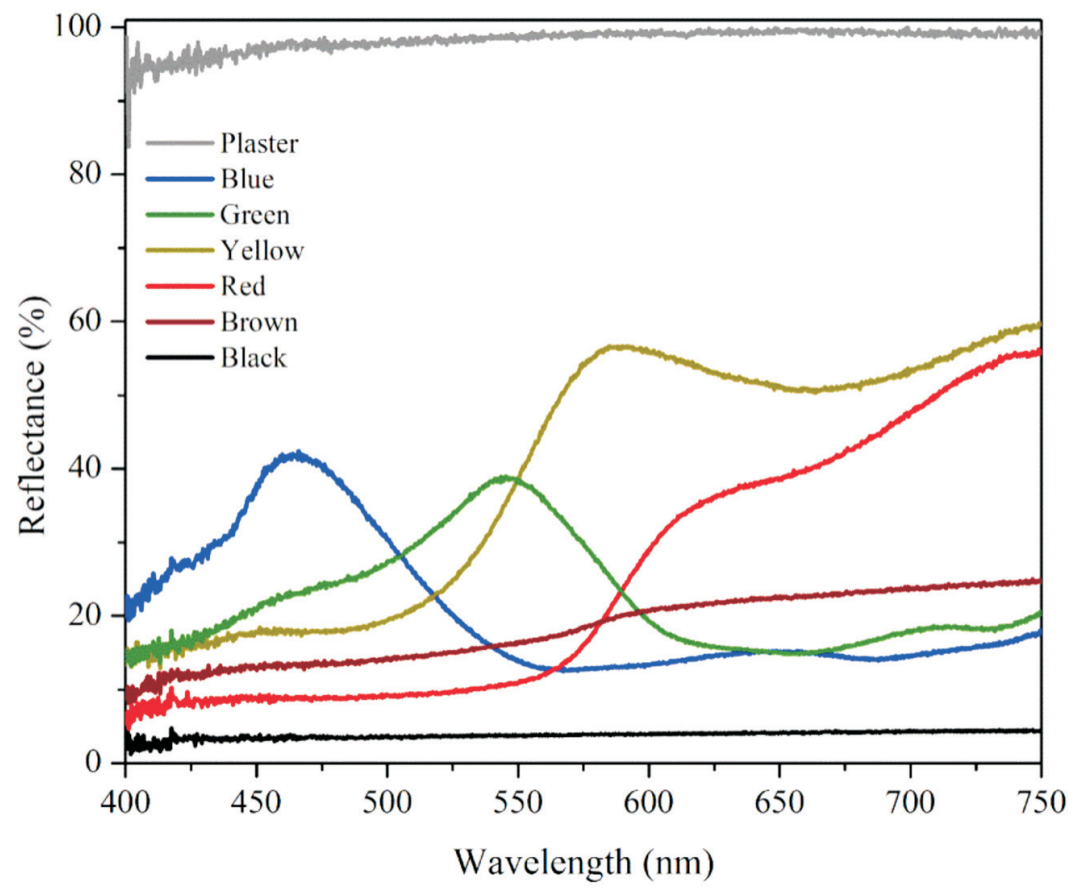

Figure 4 Electronic spectra (UV-Vis) of plaster and powder colourful commercial pigments in diffuse reflectance mode.

$1100 \mathrm{~nm}$, corresponding to the most important zone of the spectra related to heat generation, was measured, to investigate the solar reflectance NIR of the pigments. ${ }^{25}$ The reflective band in this region was detected only for the plaster and the blue pigment, which makes them 'cold' pigments, that is, they do not achieve high temperatures when exposed to solar radiation. ${ }^{26}$ For the other pigments, this behaviour was not observed, due to the iron percentage in the composition and the crystallinity values, since iron with crystalline behaviour has high absorbance in this wavelength range. ${ }^{27}$

The diffuse reflectance data were used to calculate the adjusted solar reflectance, using a pattern spectrum from standard ASTM G173 (solar disk spectral radiation, diffuse sky and soil reflection in the surface turned south and inclined to $37^{\circ}$ in the horizontal). ${ }^{15,28}$ The mean of the values are presented in
Table 3, with the highest of $44.7 \%$ for the white plaster and the lowest of $2.2 \%$ for the black pigment. The results are in accordance with the literature regarding commercial pigments. ${ }^{29,30}$

\subsection{Colorimetry - CIE L*a*b* Method}

The values of the colour parameters $\left(L^{*} a^{*} b^{*}\right)$ and the colours calculated by the software from the ColorMine library are presented in Table 3. The results obtained through colorimetric coordinates are characteristic of each pigment (Fig. 1). These come from each compound used in the production: the iron oxide pigments (yellow, red, brown and black) followed the colours of minerals derived from the element iron (goethite, hematite, magnetite and magnesium ferrite) ${ }_{i}^{15}$ the green and the blue pigments, from the organometallic copper phthalocyanine, with and without goethite in the mixture..$^{14,15}$ 

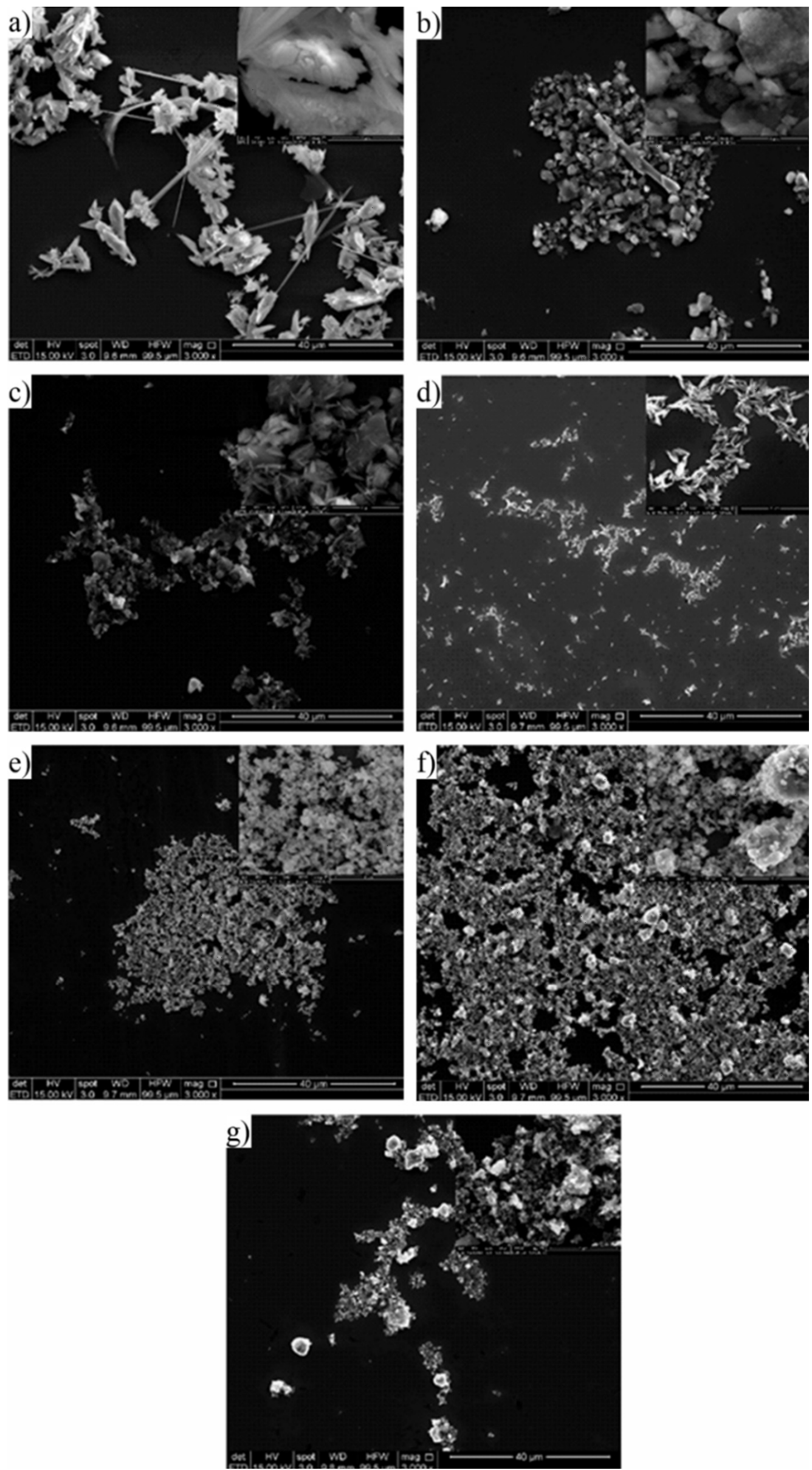

Figure 5 SEM images of plaster and colourful commercial pigments: (a) Plaster; (b) Blue; (c) Green; (d) Yellow; (e) Red; (f) Brown; (g) Black. 


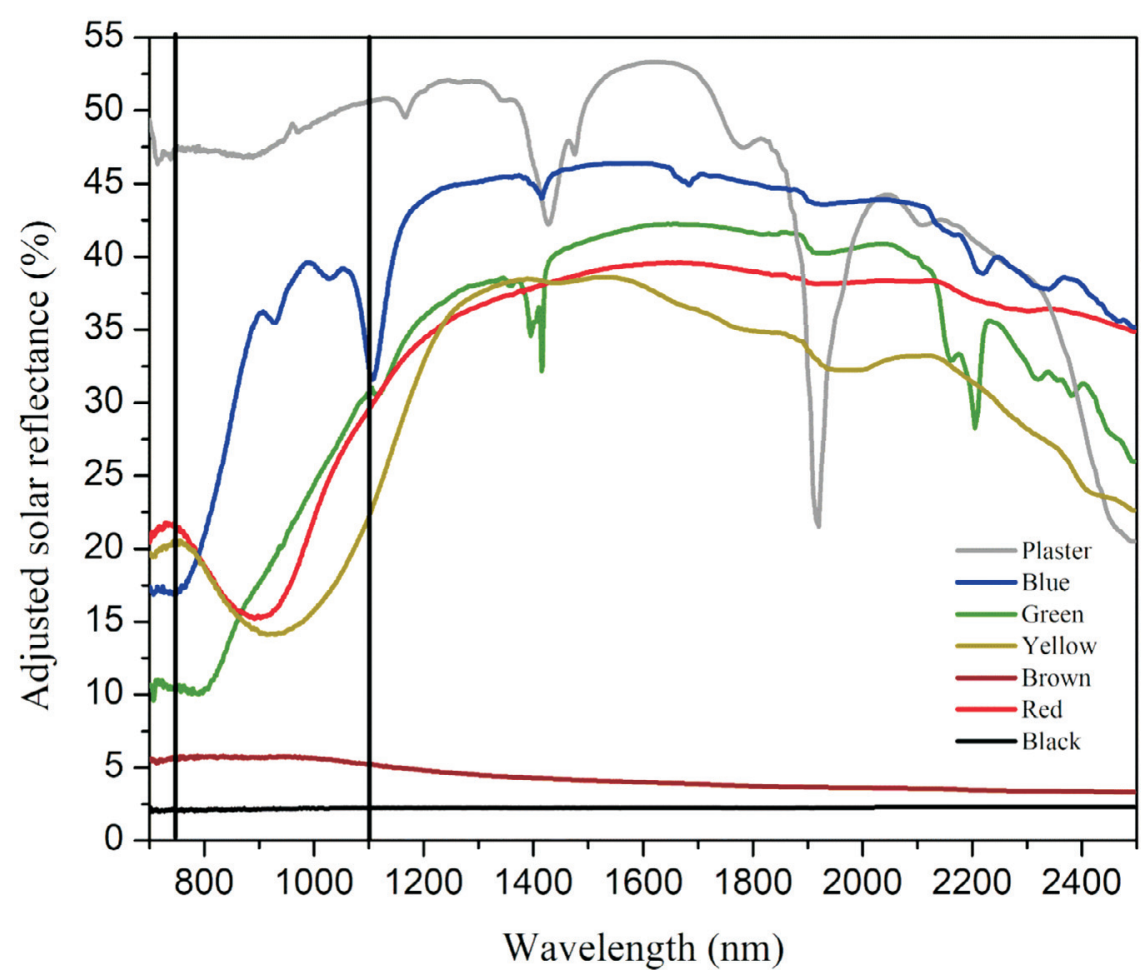

Figure 6 NIR region spectra of plaster and colourful commercial pigments.

\section{Conclusion}

The structural (XRD), morphological (SEM) and spectroscopic (XRF and UV-Vis) properties were important to identify the compounds that give colour to each commercial pigment: the

Table 3 Mean of adjusted solar reflectance and colorimetric data of plaster and colourful commercial pigments.

\begin{tabular}{|c|c|c|c|c|c|}
\hline \multirow{2}{*}{$\begin{array}{l}\text { Pigment } \\
\text { solar }\end{array}$} & \multicolumn{3}{|c|}{ Colorimetry parameters } & \multirow{2}{*}{$\begin{array}{l}\text { Software } \\
\text { colour }\end{array}$} & \multirow{2}{*}{$\begin{array}{c}\text { Adjusted } \\
\text { reflectance/\% }\end{array}$} \\
\hline & $L^{*}$ & $a^{*}$ & $b^{*}$ & & \\
\hline Plaster & 96.11 & -0.10 & 2.04 & & 44.7 \\
\hline Blue & 37.86 & -8.82 & -39.90 & & 34.1 \\
\hline Green & 57.07 & -31.69 & 18.07 & & 24.6 \\
\hline Yellow & 66.20 & 6.52 & 53.16 & & 23.6 \\
\hline Red & 38.07 & 28.28 & 23.85 & & 27.3 \\
\hline Brown & 33.61 & 9.02 & 13.62 & & 4.9 \\
\hline Black & 20.14 & -1.69 & 2.31 & & 2.2 \\
\hline
\end{tabular}

macrocyclic metalled with copper and the iron oxides (hematite, goethite and magnesium ferrite). The plaster (the white pigment) had calcium carbonate as major component and presented morphology characteristic of the $\alpha$ - and $\beta$-plaster mixture. With respect to solar adjusted reflectance, the plaster and the blue pigment presented the characteristic of 'cold' pigments. The colorimetric coordinates, using the free software ColorMine, confirmed the colours provided from the identified colourants.

\section{Acknowledgements}

Authors thank funding agencies: CNPq (310041/2016-3 and 427127/2018-1), Capes, Finep and Fundação Araucária (001/2016 - CPBA/PROPESP). K.W. Borth thanks CNPq (447902/2014-8) for a scientific initiation scholarship. Besides that, the authors are grateful for the CNPEM facilities and thank the LNNano staff for the SEM experiments.

\section{${ }^{5}$ ORCID iDs}

D. Galante: (iD) orcid.org/0000-0002-3265-2527

FJ. Anaissi: $\quad$ (D) orcid.org/0000-0002-5454-472x

M.G.P. Valenga: (iD) orcid.org/0000-0002-0962-5782

\section{References}

1 F. Bondioli, T. Manfredini and A.P.N. Oliveira, Pigmentos Inorgânicos: Projeto, Produção e Aplicação Industrial, Ceram. ind., 1998, 3, 13-17.

2 C.C.I. Guaratini and M.V.B. Zanoni, Corantes Têxteis, Quím. Nova, 2000, 23, 71-78.

3 L.W. Mckeen, Fluorinated Coatings and Finishes Handbook, 2nd edn., S.l., Elsevier, 2016.

4 Brasil. Agência Nacional de Vigilância. Resolução - CNNPA n ${ }^{\circ} 44$, de 1977. Diário Oficial [da] União. 1978 fev. 01 [accessed on 5 October 2017]. Available at:

http://www.anvisa.gov.br/anvi-salegis/resol/44_77.htm

5 C. Saron and M.I. Felisberti, Ação de colorantes na degradação e estabilização de polímeros, Quím. Nova, 2006, 29, 24-128.

6 A. Gürses, M. Açıkyıldız, K.Güneş and M.S. Gürses, Dyes and pigments: their structure and properties, in A. Gürses, M. Açıkyıldız, K. 
Güneş and M.S. Gürses, Dyes and Pigments, 1st edn., Springer, 2016, 13-29.

7 P.B.L. Constant, P.C. Stringheta and D. Sandi, Corantes alimentícios, B. CEPPA, 2002, 20, 203-220.

8 S.F. Santos, M.C. Andrade, J.A. Sampaio, A.B. Luz and T. Ogasawara, Synthesis of ceria-praseodymia pigments by citrate-gel method for dental restorations, Dyes Pigm., 2007, 75, 574-579.

9 F.Q. Mariani, K.W. Borth, M. Muller, M. Dalpasquale and FJ. Anaissi, Sustainable innovative method to synthesize different shades of iron oxide pigments, Dyes Pigm., 2017, 137, 403-409.

10 L. Cao, X. Fei, H. Zhao and Y. Gu, Inorganic-organic hybrid pigment fabricated in the preparation process of organic pigment: preparation and characterization, Dyes Pigm., 2015, 119, 75-83.

11 K. Gong, Y. Pan, L.J. Rather, W. Wang, Q. Zhou and T. Zhang, Natural pigment during flora leaf senescence and its application in dyeing and UV protection finish of silk and wool - a case study of Cinnamomum camphora, Dyes Pigm., 2019, 166, 114-121.

12 E. Ghelardi, I. Degano, M.P. Colombini, J. Mazurek, M. Schilling, H. Khanjian and T. Learner, A multi-analytical study on the photochemical degradation of synthetic organic pigments, Dyes Pigm., 2015, 123, 396-403.

13 A.F. Costa, P.M. Pimentel, D.M.A. Melo, M.S.C. Câmara, L. Chantelle, M.A.F. Melo and R.L.B.A. Medeiros, Preparação de pigmentos de aluminatos de cobalto para aplicação em vidrados cerâmicos, Ceramica, 2016, 62, 179-185.

14 J. Godleman, M. J. Almond and W. Matthews, An infrared microspectroscopic study of plasters and pigments from the Neolithic site of Bestansur, Iraq, J. Archaeol. Sci. Rep., 2016, 7, 195-204.

15 B.D. Cullity and S.R. Stock, Elements of X-ray diffraction, 3rd edn., Addison-Wesley Publishing Company, Massachusetts, 1956.

16 S. Jose, A. Jayaprakash, S. Laha, S. Natarajan, K.G. Nishanth and M.L.P. Reddy, YIn0.9Mn0.1O3-ZnO nano-pigment exhibiting intense blue color with impressive solar reflectance, Dyes Pigm., 2016, 124, 120-129.

17 M.C.F. Karlsson, Z. Abbas, R. Bordes, Y. Cao, A. Larsson, P. Taylor and B.M. Steenari, Characterisation of silicon, zirconium and aluminium coated titanium dioxide pigments recovered from paint waste, Dyes Pigm., 2019, 162, 145-152.

18 D.L.A. Faria and T.S. Pugliari, Um exemplo de aplicação da microscopia raman na autenticação de obras de arte, Quím. Nova, 2011, 34, 1323-1327.
19 R.S. Oliveira, M.R.S. Oliveira, S.C. Oliveira and E.A. Ponzi, Materiais eletrocrômicos orgânicos: uma breve revisão de viológenos, ftalocianinas e alguns complexos de mateis de transição, Rev. Virtual Quím., 2013, 5, 596-629.

20 D. Dini and M. Hanack, Phthalocyanines as materials for advanced technologies: some examples, J. Porphyr. Phthalocyanines, 2004, 8, 915-933.

21 L. Madriz, J. Tatá, V. Cuartas, A. Cuéllar and R. Vargas, Celdas solares fotoelectroquímicas basadas em Bi2WO6, Quím. Nova, 2014, 37, 226-231.

22 R. Bairak, M. Durmus, S. Meydanal, S. Kemal and I. Değirmencioğlu, Synthesis, structural and spectroscopic characterization, and photophysical and photochemical properties of peripherally tetratriazole-subsituted highly soluble metallophthalocyanines, Polyhedron, 2012, 48, 1-8.

23 U. Hempelmann and V. Schneider, High colour purity iron oxide red, European Coatings J., 2004, 20.

24 A.A. Barbosa, A.V Ferraz and G.A. Santos, Caracterização química, mecânica e morfológica do gesso $\beta$ obtido do pólo do Araripe, Ceramica, 2014, 60, 501-508.

25 W. Bao, F. Ma, Y.T. Zhang, Z.F. Deng, X.Y. Zou and W. Gao, Synthesis and characterization of $\mathrm{Fe} 3+$ doped $\mathrm{Co} 0,5 \mathrm{Mg} 0,5 \mathrm{Al} 2 \mathrm{O} 4$ inorganic pigments with high near-infrered reflectance, Powder Technol., 2016, 292, 7-13.

26 R. Levinson, H. Akbari and J. Reilly, Cooler tile-roofed buildings with near-infrared-reflective non-white coatings, Build. Environ., 2007, 42, 2591-2605.

27 J.A.M. Demattê, S.R. Araújo, P.R. Fiori, C.T. Fongaro and M.R. Nanni, Espectroscopia Vis-NIR-SWIR na avaliação de solos ao longo de uma topossequência em Piracicaba (SP), Rev. Ciênc. Agron., 2015, 46, 679-688

28 A. Synnefa, M. Santamouris and K. Apostolakis, On the development, optical properties and thermal performance of cool colored coating for the urban environment, Sol. Energy, 2007, 81, 488-497.

29 D.A. Luxmoore, M.T.R. Jayasinghe and M. Mahendran, Mitigating temperature increases in high lot density sub-tropical residential developments, Energy Build., 2005, 37, 1212-1224.

30 S. Bretz, H. Akbari and A. Rosenfeld, Pratical issues for using solarreflective materials to mitigate urban heat islands, Atmos. Environ., 1998, 32, 95-101. 